\title{
Factors affecting dairy farmers' attitudes towards antimicrobial medicine usage in cattle in England and Wales
}

Article

Accepted Version

Jones, P. J., Marier, E. A., Tranter, R. B., Wu, G., Watson, E. and Teale, C. J. (2015) Factors affecting dairy farmers' attitudes towards antimicrobial medicine usage in cattle in England and Wales. Preventive Veterinary Medicine, 121 (1-2). pp. 30-40. ISSN 0167-5877 doi:

https://doi.org/10.1016/j.prevetmed.2015.05.010 Available at https://centaur.reading.ac.uk/41559/

It is advisable to refer to the publisher's version if you intend to cite from the work. See Guidance on citing.

To link to this article DOI: http://dx.doi.org/10.1016/j.prevetmed.2015.05.010

Publisher: Elsevier

All outputs in CentAUR are protected by Intellectual Property Rights law, including copyright law. Copyright and IPR is retained by the creators or other copyright holders. Terms and conditions for use of this material are defined in the End User Agreement. 


\section{CentAUR}

Central Archive at the University of Reading

Reading's research outputs online 
1 Factors affecting dairy farmers' attitudes towards antimicrobial medicine usage in

2 cattle in England and Wales

$3 \quad$ P. J. Jones ${ }^{a}$, E. A. Marier ${ }^{b}$, R. B. Tranter ${ }^{a^{*}}$, G. Wu ${ }^{b}$, E. Watson ${ }^{b}$ and C. J. Teale ${ }^{b}$

$4{ }^{a}$ Centre for Agricultural Strategy, University of Reading, Earley Gate, PO Box 237, Reading, 5 RG6 6AR, UK.

$6 \quad{ }^{b}$ Animal and Plant Health Agency, New Haw, Addlestone, Surrey, KT15 3NB, UK.

7

$8 \quad{ }^{*}$ Corresponding author.

$9 \quad$ Tel.: +44 (0) 118 3788155. E-mail address: r.b.tranter@reading.ac.uk

11 Abstract

12 There has been growing concern about bacterial resistance to antimicrobials in the farmed livestock sector. Attention has turned to sub-optimal use of antimicrobials as a driver of resistance. Recent reviews have identified a lack of data on the pattern of antimicrobial use as an impediment to the design of measures to tackle this growing problem. This paper reports on a study that explored use of antibiotics by dairy farmers and factors influencing their decision-making around this usage.

We found that respondents had either recently reduced their use of antibiotics, or planned to do so. Advice from their veterinarian was instrumental in this. Over $70 \%$ thought reducing antibiotic usage would be a good thing to do. The most influential source of information used was their own veterinarian. Some $50 \%$ were unaware of the available guidelines on use in cattle production. However, $97 \%$ thought it important to keep treatment records. 
23 The Theory of Planned Behaviour was used to identify dairy farmers' drivers and barriers to

24 reduce use of antibiotics. Intention to reduce usage was weakly correlated with current and past practice of antibiotic use, whilst the strongest driver was respondents' belief that their social and advisory network would approve of them doing this. The higher the proportion of income from milk production and the greater the chance of remaining in milk production, the significantly higher the likelihood of farmers exhibiting positive intention to reduce antibiotic usage. Such farmers may be more commercially minded than others and thus more costconscious or, perhaps, more aware of possible future restrictions.

Strong correlation was found between farmers' perception of their social referents' beliefs and farmers' intent to reduce antibiotic use. Policy makers should target these social referents, especially veterinarians, with information on the benefits from, and the means to, achieving reductions in antibiotic usage. Information on sub-optimal use of antibiotics as a driver of resistance in dairy herds and in humans along with advice on best farm practice to minimise risk of disease and ensure animal welfare, complemented with data on potential cost savings from reduced antibiotic use would help improve poor practice. 


\section{Introduction}

At a therapeutic level, antimicrobials are vital medicines for treatment and control of bacterial infections. However, there are increasing reports of resistance to antimicrobial drugs used in veterinary medicine and, also, concerns about the threat that may pose to both animal and human health, through the selection of resistance (WHO, 2000; Marshall et al., 2011; WHO, 2014a). Development of antimicrobial resistance also threatens to restrict the effectiveness of existing drugs used on farms and the treatment of veterinary bacterial pathogens.

There is increasing evidence that overuse and sub-optimal use of antimicrobials may be a factor in the development of bacterial resistance to veterinary antimicrobials (e.g. Barbosa and Levy, 2000). Antimicrobial stewardship is now internationally recognised as a challenge. A multifaceted approach - concerted effort between industry and government bodies and a variety of initiatives including alternatives to antibiotics and a better consumption recording system - is required to optimise the use of antibiotics (Prescott, 2014).

In response to these concerns, several countries (Denmark, France, the Netherlands and the UK) have developed strategies for monitoring incidents of bacterial resistance in farm animals, as a first step towards designing measures to reduce antimicrobial usage and for promoting prudent and responsible use of antimicrobials by farmers, farm staff and veterinarians (Anon, 2007; Anon, 2012a; Anon, 2013; Anon, 2014a; EPRUMA, 2008; Landers, 2012; Levy, 2014; OIE, 2013 and WHO, 2014b). In 2011, the European Commission (EC) launched a 5-year action plan, including 12 actions to tackle antimicrobial resistance covering areas such as 'development of new effective antimicrobials or alternative treatment', 'improving surveillance and monitoring in human and animal medicine' and ‘making sure antimicrobials are used appropriately’ (Anon, 2011).

In the UK, various guidance on best practice for the responsible use of antimicrobials in livestock is available to farmers and veterinarians such as that published by Responsible Use of Medicines in Agriculture (RUMA) alliance (RUMA, 2004). The British Veterinary 
Association (BVA) has actively promoted responsible use of antimicrobials to veterinarians, most notably by publishing a poster with a simple and effective 8-point plan (Anon 2009). In 2013, the UK Government published the 'UK Five Year Antimicrobial Resistance (AMR) Strategy 2013 to 2018', in line with the 2011 EC strategy, which proposed actions to slow the development and spread of AMR (Anon, 2013) and in 2014, the British Cattle Veterinary Association published a poster on medicine residues in milk for farmers (BCVA, 2014). While guidance documents have been published, there has been little or no assessment of the impact of the recommendations on farming practices and on antimicrobial consumption. Antibiotic sales for all food producing animals have remained relatively stable between 2008 and 2013 despite the guidance. Furthermore, recommendations on the appropriate first and second antimicrobial treatments for specific conditions have been adopted in other European countries (e.g. the Netherlands (Teale and Moulin, 2012) and Denmark (Pedersen et al., 1999)) but not in the UK.

The Veterinary Medicinal Product Directive 2001/82/EC sets out the control on veterinary medicines. This EC Directive provides the basis for UK controls which are applied through the Veterinary Medicines Regulations. All veterinary medicines, including those containing antibiotics, require authorisation before they are marketed or administered to animals. All antibiotic veterinary medicines in the UK must be prescribed by a veterinarian. Routine prophylactic use of antibiotics is not a recommended practice by the Veterinary Medicines Directorate (VMD) in the UK (Anon., 2014c); and the prophylactic use of antibiotics at very small doses in animal feed - better known as growth promotors - has been banned in the European Union (EU) since 2006 (Regulation 1831/2003/EC on additives for use in animal nutrition).

Nevertheless, how medicines are prescribed is down to the professional judgement of the veterinarian which can be influenced by various factors. A study suggested that widely differing patterns of antimicrobial usage exist between 10 European countries. These 
patterns could not be explained by simple differences in animal species demographics which suggests that other factors, such as farm management or social factors were involved (Grave et al., 2010). The Heads of Medicines Agencies across the EU worked in collaboration with the Federation of Veterinarians of Europe to explore antimicrobial prescribing habits and influencing factors among veterinarians for food producing animals, companion animals and equines (De Briyne et al., 2013). That survey confirmed that veterinarians were most likely to prescribe antimicrobials following sensitivity test results but also based on their experience and ease of use in the absence of test results. Similarly, another study which looked at antimicrobial use in a companion animal teaching hospital in Italy concluded that there was a need to improve procedures for antimicrobial prescription; published guidelines with further implementation of policies of prudent prescriptions were suggested (Escher et al., 2011).

Although veterinarians are usually responsible for choosing the appropriate antimicrobials for treatments, choices may also be influenced by farmers' own opinions and needs based on, for example, cost and profit margin, ease of medicine administration and withdrawal period (De Briyne et al., 2013; Gibbons et al., 2013). Then, once prescribed, little is known on how medicines are administered and managed by the farmers and whether alternative practices are taken into consideration by the farmer to reduce reliance on antibiotics.

Until 2013, direct marketing of veterinary antimicrobials by animal health companies to farmers was permitted in the UK, unlike in mainland Europe, where such advertising has been banned since 2011 (Anon, 2012b), on the grounds that information supplied may not be used or interpreted adequately by farmers. Indeed, in a study which explored farmers' knowledge and attitudes towards antimicrobial usage in livestock, a lack of knowledge about antimicrobials and bacterial resistance was highlighted (Friedman et al., 2007). For example, it was found that farmers mostly relied on their own or a neighbour's experience rather than scientific evidence or advice from their veterinarian to decide which treatment to adopt. 
118 Though veterinarians were the main source of information, limited finances for expenditure

119 on veterinary support was a key barrier to seeking out antibiotic protocols (Friedman et al.,

120 2007). If factors other than those directly related to the effective treatment of disease (whilst

121 minimising the emergence of resistance) have a large impact on the eventual therapy

122 selected and subsequently applied, then these factors (e.g. marketing, price, availability,

123 neighbour's experience) are potentially an important issue to consider.

124 Clearly, legislation would over-ride any drivers and barriers but in the absence of legislation

125 to reduce antimicrobial usage the question remains:

126 'What factors (knowledge, social, economic) could influence farmers' perceptions,

127 attitudes and behaviours in participating in an animal health management programme

128 relating to prudent usage of antimicrobials?'

129 To help ensure the responsible use of antimicrobials as a disease control measure on dairy

130 farms, further research is needed to understand farmers' and veterinarians' behaviour and

131 attitudes towards their use, and to identify which factors and motives are most important in

132 influencing current and proposed practice (Busani et al., 2004).

133 Understanding farmer attitudes and the factors that influence decision-making and the

134 translation of intentions into sustained changes in behaviour, is seen as an increasingly

135 useful discipline in policy making and health scheme implementation. The relatively small

136 scale survey described here is part of the larger Emerging and Major Infectious Diseases in

137 Animals (EMIDA) initiative. The overarching objective of the EMIDA project was to gain

138 insight into the determinants of behaviour that influence farmers' willingness to participate in

139 animal health management programmes. As a starting point, this pilot study aimed to: look

140 into the extent to which recommended guidance on responsible veterinary use of

141 antimicrobials in England and Wales is being followed by farmers; explore reasons why 
142 deviations from prudent use by farmers may be occurring; and identify the factors influencing

143 farmers' decisions on antimicrobial usage.

144

145

146

147

\section{Method}

\subsection{Procedure}

Data on farmer attitudes and behaviours connected with antimicrobial use were collected by a postal survey of dairy farmers in England and Wales. The researchers developed a questionnaire based on the Theory of Reasoned Action (TORA) and Theory of Planned Behaviour (TPB) and relevant literature (e.g. Ajzen, 1991; Fishbein and Yzer, 2003; Garforth et al., 2006 and Garforth et al., 2013). It was then piloted with 5 farmers.

The questionnaire had 7 sections with questions on: the farmer and their dairy enterprise; use of antibiotics and attitudes towards use of antibiotics; and knowledge on guidelines for their use. Attitudinal questions were framed on a 5-point Likert scale system, while a choice of answers was provided for the socio-demographic questions.

The 8 page A4-size questionnaire was sent out in July 2013 with a covering letter explaining the survey objectives with a reply-paid envelope. It went to 118 farmers who had agreed to be involved in the research out of the 250 random sample of dairy farmers initially approached to take part. Questionnaires in both English and Welsh were provided to farmers in Wales. A copy of the questionnaire is available from the corresponding author. To maximise response rate, a reminder letter with a duplicate copy of the questionnaire was sent out in August 2013 and again in September 2013. The survey was closed on 30 September 2013.

\subsection{Survey representativeness}

Demographic characteristics were verified to ensure that the sample was representative of the population from which it was drawn. Table 1 shows some characteristics of the respondents and their dairy herds. Survey farmers were mostly (64\%) over 50 years and 
experienced with an average of 35.3 years working in the dairy industry. These demographics compare well with official statistics which show that the mean age of farmers in the UK in 2010 was 59 years old, with only 39\% under 55 years old (Defra, 2013a).

The mean herd size of the respondents was 180 adult cows, while the England mean for 2013 was 134 (DairyCo, 2013). The mean yield of the respondents' cows was 7487 I/cow and the mean price for their milk was $31.1 \mathrm{p} / \mathrm{l}$; Defra (2013a) figures were $7445 \mathrm{l} / \mathrm{cow}$ and $28.1 \mathrm{p} / \mathrm{l}$. Thus, for five measures, the survey sample matched dairy farmers overall well, although the sample herd size was somewhat larger than the national average.

Survey non-response bias was assessed by comparing the observable characteristics of the first 30\% replying against those of the last 30\% replying. When the comparison was made for these measures, it was found that there were no statistically significant differences between the 'early' and 'late' responders and that 'non-response' bias was unlikely to be present. If there had been a significant difference it could have been concluded that those not replying at all would be likely to be comparable to the 'late' responders (Armstrong and Overton, 1977; Barclay et al., 2002; Groves, 2006; MacDonald et al., 2009).

\subsection{The theoretical model used}

183 To develop successful interventions to change particular behaviours, such as reducing

184 farmers' use of antibiotics, it was necessary to understand the determinants of that behaviour. In recent years there has been more recognition of the usefulness of behavioural theory in understanding the determinants of behaviour (e.g. Fishbein and Cappella, 2006). While several behavioural theories have been developed, taken together they have shown that only a few variables need to be taken into account in understanding, and even predicting, a given behaviour (Fishbein, 2000). A model that brings together these variables, capturing both internal (i.e. psychological) and external (e.g. cultural and population) factors is TPB (Ajzen, 1991; Fishbein and Yzer, 2003). 
192 The theory states that a person's 'intention' to perform a particular behaviour is the best

193 predictor of whether they actually do so. The theory also identifies three determinants that 194 influence the intention to perform a behaviour:

195

196

197

199

200

201

202

203

204

205

206

207

i) attitude towards the expected outcome of the behaviour (Outcome Attitudes) i.e. what they expect the outcome of their behaviour to be, and the value placed on it;

ii) beliefs about what valued others expect them to do in relation to the behaviour (Normative Referents); and

iii) beliefs about their ability to implement the behaviour (Perceived Behavioural Control).

TPB suggests that more favourable attitudes towards the outcomes of the behaviour, more favourable opinions of valued peers towards the behaviour, and greater perceived behavioural control strengthen the intention to perform the behaviour.

The TPB framework allowed us to understand why some members of the target population intended to undertake this behaviour and others not, through identification of the relative influences of attitudes (towards reduced use of antibiotics), normative referents (opinions of peers) and perceived behavioural control perceptions, as well as socio-demographic characteristics, on behavioural intent (intent to reduce use of antibiotics in the next year). A focus was made on the roles of the above as drivers and barriers to the development of this intention. Once understood in this way, these drivers and barriers will inform the design of messages and other interventions to impact well on this target behaviour.

\subsection{Statistical analysis}

Data were transcribed from the returned questionnaires to create an electronic Excel dataset. Data quality checks were carried out to ensure correct data entry and accurate transcription. Data analysis was carried out using SAS Version 9.3, SAS Inc., Rayleigh, 
215 North Carolina, USA. The questionnaire elicited three types of information relating to

216 farmers' use of information to support their decisions on livestock disease control measures:

217 i) frequency of use of the different sources;

218 ii) a rank for the amount of information obtained from each source; and

iii) a rank for the value placed on the opinions of each source.

220 These information types were put into a combined measure of the broad level of influence $(I)$

221 of each source. First, the ranking of the amount of information provided $(\bar{x} a)$ was weighted by the value placed on each source $(\bar{x} b)$. The product $(\bar{x} a \cdot \bar{x} b)$ was then weighted by the frequency of nomination of each source $(n)$ and then divided by the number in the sample $(N)$ to rebase to a zero to 25 rating scale. In equation form, the calculation was:

$$
I_{j}=\frac{\left(\left(\bar{x} a_{j} \times \bar{x} b_{j}\right) \times n_{j}\right)}{N}
$$

Where: $\quad l_{j}=$ Influence of source $(j)$

$$
N=\text { Total number in sample }(N=71)
$$
$n=$ Number nominating source (j) $\bar{x} a j=$ Mean rank of amount of information supplied from source $(j)$ $\bar{x} b j=$ Mean rank of value attached to source $(j)$

The questionnaire had no single direct measures for two of the behavioural components traditionally used in TPB analysis i.e. outcome attitudes (OA) (beliefs about the outcomes of reduction in antibiotic use) and perceived behavioural control (PC). These components were measured indirectly via a suite of targeted questions. In the case of normative referents i.e. subjective norms (SN), there was a candidate for direct measurement which was assessed alongside a composite construction of the same component. Composite variables were calculated for each of the components (OA, SN and PC) by summing the rank scores over the contributing questions $(I)$. All SN, and some PC, 5-point rank scores $(b)$ were weighted 
by a 5-point importance score (e) before aggregation, while all OA and some PC questions were un-weighted.

Cronbach's Alpha was calculated to test the coherence of each of the three composite components. A high Cronbach's Alpha (>0.6) indicated that the items contributing to a measure, when summed, produced a coherent composite measure. Because of the variation in the ranges of the TPB measures, the standardised Cronbach's Alpha Coefficient was used. In each of the three composite TPB measures, even when coherence based on available items exceeded 0.6 , one or more of the contributing questions was deleted in order to maximise coherence.

The coherence of each of the three composite components of behaviour are shown in Table 7. One or more of the contributing questions deleted from the analysis were included individually in the correlation analyses reported below and are in italicised text in Table 9.

The TPB variables identified as correlated with intent were used with variables representing farmers' socio-demographic characteristics in a regression model to predict intention (the dependent variable) to reduce antibiotics use over the next 12 months. As the dependent variable was based on an ordinal scale, and some of the independent variables had ordinal or binary scales, a multivariate logistic regression was undertaken. Specifically, a cumulative logit model was fitted using the SAS LOGISTIC procedure. Variables were manually removed from the regression model where they yielded non-significant Maximum Likelihood Estimates (MLE), beginning with the variable with the highest $\mathrm{P}>\mathrm{Chi} \mathrm{Sq}$ value. This process was repeated until all remaining variables had significant MLEs.

\section{Results}

\subsection{Descriptive measures of the respondents and their dairy herds}

Seventy one sufficiently completed responses were received $(28.4 \%$ of those initially approached). Only one spoilt questionnaire was returned and, thus, was excluded from the 
dataset. Of the total sample of respondents of $71,60(85 \%)$ farmed conventionally with the remaining 11 respondents being wholly, or largely, organic. Most respondents (80\%) housed their dairy cows for at least 6 months of the year. The mean total milk production was 1.17 million litres per farm per year with a range from 250,000 litres to 6.1 million litres.

The Rolling Somatic Cell Count for a 12 month period ranged widely from 65,000 per $\mathrm{ml}$ to 337,000 per $\mathrm{ml}$ with a mean of $186,708 \mathrm{per} \mathrm{ml}$. The national mean for 2013 was 199,000 cells/ml (Anon., 2014). It can be concluded that the survey respondents had a marginally better Somatic Cell Count than dairy farmers nationally.

All respondents had farm income sources other than from their dairy enterprise, with a third deriving $25 \%$ of their farm income from non-dairy activities. The mean milk price obtained by respondents at the time of survey was 31.1 pence per litre ranging from 24.7 to 38.0 pence per litre. Some 30 different milk buyers were listed by the respondents with the most common being: ARLA, Dairy Crest, First Milk, Mueller, OMSCO and Wiseman.

Membership of Assurance and Certification Schemes was common for survey farmers with 67 of the 71 belonging to at least one Scheme. Of respondents who were in an Assurance Scheme, some $50 \%$ were required by that Scheme to act relating to antibiotic use.

Almost all (69) of the 71 respondents had a Herd Health Plan and, for the 48 who indicated when it was last revised, the mean year was 2012; of these respondents, $58 \%$ stated when they last consulted their plan, with a mean year of 2008 . It was found that $7 \%$ had a routine visit from their veterinarian weekly, $23 \%$ fortnightly, and $70 \%$ monthly or less.

Those surveyed were asked 'Looking ahead, how likely is it that your dairy enterprise will still be operating in 5 years' time?'. This needs to be contextualised by figures in DairyCo (2013) that showed a steady decline in the number of UK dairy herds over the last decade to less than 10,000 . Around $16 \%$ of respondents said they were either very unlikely or unlikely to be still operating in 5 years' time, $8 \%$ said they were neither likely nor unlikely to be, whereas 
$69 \%$ said they were either likely or very likely to be still running their dairy enterprise in 5 years' time. The remaining 7\% said they did not know what they would be doing.

Respondents were asked to indicate their highest level of educational attained. The most commonly experienced type/level of education by $44 \%$ was 'Further education (agriculture related)'. This is consistent with Defra (2013b) findings for farmers in the Farm Business Survey. The proportion having a university degree in an agriculture related subject (26\%) was somewhat higher than that reported by Garforth et al. (2006) and Tranter et al. (2011).

\subsection{Current and future use of antibiotics}

Almost $59 \%$ of respondents reported that their antibiotic use was 'about the same as a year ago' and $37 \%$ said 'less frequently than a year ago'. The reasons for the decline in the use of antimicrobials were circumstantial, rather than planned i.e. a fall in the incidence of mastitis, and drier weather leading to healthier cows and less lameness. In terms of intentions regarding antibiotic usage over the next year, $42 \%$ said they strongly intended to reduce antibiotics use, while $52 \%$ were neutral and only $6 \%$ were weakly motivated to do so.

Table 2 shows how respondents ranked these statements by their level of agreement where the lower the mean ranking score, the higher their level of agreement with the statement. The highest level of agreement was achieved with the statement about following best practice in all aspects of antibiotic use and fully recording such use.

For the other eight statements there was more variation in responses. For example, there was little agreement on whether 'The use of antibiotics in dairy herds leads to antibiotic resistance in dairy cows' (mean ranking score: 2.78) and 'Preventative use of antibiotics in the dairy herd helps me meet production goals' (mean ranking score: 3.03 ). Whilst only $6 \%$ agreed that antibiotic usage in dairy farming was a major cause of antibiotic resistance in humans, $22 \%$ agreed that 'If every dairy farmer followed best practice, there would be less 
resistance to antibiotics in the human population'. Nevertheless, $68 \%$ agreed that human

314 infections resistant to antibiotics were a serious problem (mean ranking score: 2.26).

315 Almost $60 \%$ of the respondents agreed with the two resource-use based statements - 'If all dairy farmers followed best practice in the use of antibiotics, overall use of antibiotics would fall' and 'Antibiotics are expensive and I minimise usage to reduce costs' - although, with the second of these statements, $25 \%$ disagreed, implying that cost was not a factor in how they used antibiotics. Finally, 55\% seemed not to ask advice from their veterinarian before using antibiotics on their cows, with just 17\% doing so (mean ranking score: 3.42 ). This implies, possibly, that farmers used antibiotics, from time to time, from those 'held back' from previous prescriptions as a perceived way of saving money and such 'under-dosing' is an important risk factor for antibiotic resistance.

To gauge respondents' current antibiotics use practice, they were presented with a set of 12 health problem scenarios that might occur in a dairy herd and asked how likely or unlikely (on a 5 point scale) they would be to use antibiotics in the next year to treat them. This allowed a more comprehensive review of practices, rather than one limited to recent personal experience. Table 3 summarises respondents' answers. Farmers were more likely to use antibiotics for some health conditions than others, with the most likely being: 'Clinical mastitis with watery milk' (90\% of the respondents); 'Calf pneumonia' (89\%); and 'Clinical mastitis clots' (83\%). In contrast, the health problem scenarios that they were least likely to use antibiotics for were: 'High cell count cows and cows with repeated cases of clinical mastitis' (71\%); 'digital dermatitis' (71\%); and 'Lame cow before trimming' (67\%).

\subsection{Attitudes towards use of antibiotics in their dairy herds}

Just over $70 \%$ of respondents agreed with the statement that 'Reducing the use of antibiotics in my dairy herd over the next year would be a good thing to do' with only $6 \%$ disagreeing with it. Around $58 \%$ agreed that 'People I respect in the industry would approve of my reducing the use of antibiotics in my herd over the next year'. 
Nearly $59 \%$ of respondents said they had the skills and knowledge needed to reduce antibiotics use in their herds in future, whilst $39 \%$ were not sure. Almost $32 \%$ agreed that 'Reducing the use of antibiotics in my dairy herd over the next year would be difficult to achieve' but $19 \%$ disagreed with this statement and the remaining $49 \%$ were not sure.

Table 4 shows why farmers thought it would be good to reduce antibiotic usage in their herd.

344 The most cited benefit was cost reduction ( $64 \%$ of respondents). Only $18 \%$ thought that milk output would decline, and $15 \%$ thought it would decrease resistance in the human population if farmers reduced their antimicrobial usage, but there was a high level of uncertainty on the impact on the health of their cows (56\% unsure). When asked whether reductions in antibiotic usage would lead to loss of animal welfare, there was a fairly even spread of responses with $27 \%$ agreeing, $37 \%$ disagreeing and $36 \%$ being unsure. There was considerable uncertainty in relation to health, however, with $56 \%$ not sure and $20 \%$ believing that health would be worse. There was also much uncertainty over whether reducing antibiotic use would reduce the incidence of bacterial antibiotic resistance with $45 \%$ uncertain and $18 \%$ believing that this benefit would not be delivered.

Farmers were asked to rank a list of business and management outcomes in terms of their importance to assess a range of motivations and goals that underpin their business decisions (Table 5). Dairy enterprise profitability, and animal health and welfare, were highly important drivers of farmer decision-making, with cost minimisation close behind. In addition, quite highly rated was concern that consumers remained confident in milk safety, as this underpinned the marketability of milk and the price obtained. Relative to these concerns, the issue of antibiotic resistance was viewed as of lesser importance, especially in connection with such resistance in humans. This may be a reflection of the farmers' view of these being issues over which they had little direct control.

\subsection{Sources of information used to inform disease control}


364 Farmers looked to a range of different people and organisations for advice on farming

365

366

367

matters including on the use of antibiotics in dairy herds. Respondents were, therefore, asked the extent to which these social referents would approve of them reducing their use of antibiotics over the next year. The results are summarised in Table 6.

Few farmers thought that any of their social referents would disapprove of them reducing their use of antibiotics in the next year except for $14 \%$ of respondents who thought their private veterinarian would. However, there was variation in the perceived level of approval. Based on approval ratings, the social referents were divided into two groups. The higher approval group was the end users, or consumers, of the milk produced (milk buyer and retail consumer) whereas the lower approval group was the industry or peers (family, other farmers and the NFU). Private veterinarians fell between these two groups.

The most influential source of information on antimicrobial use was farmers' own veterinarian (Figure 1). Indeed, veterinary source scores were close to the theoretical upper maximum possible for this measure. As all respondents scored this source highly, there was little variation in appreciation of the source across sub-groups in the sample.

\subsection{Knowledge of guidelines on use of antibiotics}

Around 53\% reported some level of awareness of the RUMA (2004) guidelines on use of antimicrobials in cattle production, but half of these admitted to an incomplete knowledge. For those aware of the guidelines, 36\% followed the guidelines fully, 39\% partially followed them and $25 \%$ remembered the broad outline of the details only.

Those not aware of the RUMA (2004) guidelines were further questioned to determine the extent to which they unwittingly followed the guidelines. This revealed that $89 \%$ agreed that it is important to have written protocols for administering antibiotics to minimise mistakes, even though $70 \%$ thought this was time-consuming and just $31 \%$ said they always consulted their veterinarian if they had left-over antibiotics they wanted to use. 
Some $80 \%$ of respondents always finished the prescribed course of antibiotics even if their animals stopped showing signs of illness, while $14 \%$ modified the dosage either for convenience or because the animals did not respond as expected. As many as $96 \%$ agreed with the statement 'I always store medicine in the required conditions'. Around 97\% agreed with the statement 'It is important to keep treatment records'. Despite this, it should be acknowledged that there might be a gap between what respondents said they will do and what they actually do, the so-called social desirability bias (Crowne and Marlow, 1960).

Respondents were asked whether they were aware of concerns about inappropriate use of third and fourth generation cephalosporins leading to increased antibiotic resistance in both people and animals: $66 \%$ were aware. Level of awareness of the issues was not correlated to attitudes to first use of cephalosporins in the treatment of a range of conditions, with exception of 'a lame cow before hoof trimming'. In this case, there was a significant positive correlation $(P \leq 0.0168)$ suggesting that higher levels of awareness resulted in a lower likelihood of cephalosporins use as a first choice for treatment. A follow-on question asked whether they agreed or not that cephalosporins should not be used for preventative treatments in healthy animals: $48 \%$ agreed, $32 \%$ were neutral and $20 \%$ disagreed.

\subsection{Intention to use antibiotics using the TPB framework}

Correlation of 'intention' measures revealed a strong positive linear relationship (Spearman's Rho $=0.477, P<0.0001$ ) which suggested that combining them would add little, if any, new information. For the purpose of this analysis therefore, the single measure of strength of personal intent to reduce antibiotic usage was employed as the dependent variable.

Intention to reduce antibiotic usage was only very weakly correlated with a number of variables capturing current antibiotic use practice as measured by monetary expenditure on antibiotics (Pearson's Rho $=0.186, p=0.2994)$, and recent changes in the frequency of antibiotic use (Spearman's Rho $=0.142, p=0.2401$ ). These variables were, therefore, excluded from further analysis of the drivers of intention to reduce usage of antibiotics. 
415 Correlation analysis showed that, of the three composite measures, only the OA measure

416 had any significant relationship to intent. In light of this, the composite SN measure was

417 dropped and the single direct measure was substituted, as this variable was seen to be correlated with intent. This SN measure was based on the following question, with elicited responses ranked on a 5-point Likert scale:

420 'People I respect in the industry would approve of my reducing the use of antibiotics in my herd over the next year.'

422 Figure 2 shows the correlations between the OA, SN (single question direct measure), and 423 perceived behavioural control measures with intention to reduce use of antibiotics. Because 424 intention is reflected using an ordinal scale, Spearman's Rho statistics $\left(r_{s}\right)$ were generated to help decide which variable to keep for further analysis. Both OA and SN were seen to be positively and significantly correlated with intention, while perceived behavioural control was not significantly correlated.

428 As shown in Figure 2, OA were positively correlated with SN, but uncorrelated with perceived behavioural control (Table 8). As only the OA variable showed significant correlation with intent, intent was correlated with individual OA questions only. A significant positive correlation between an attitude question and intention indicated a cognitive driver and a significant negative correlation indicated a cognitive barrier. Table 9 shows that just 4 of the 13 attitudinal questions (i.e. attitudes to perceived outcomes of reducing antibiotic use) were significantly correlated with intent, with only three showing relatively strong associations (i.e. $r_{s}$ values of near 0.3 or greater) being:

i) 'Reduced use of antibiotics in my herd over the next year would be a good thing to do';

ii) 'Reduced use of antibiotics over the next year would lower my costs'; and

iii) 'Reduced use of antibiotics over the next year would increase consumer confidence in the safety of milk and milk products'. 
440 It is noteworthy that the questions correlating most strongly with intent were based on

441 outcomes specific to the issue of reduced use of antibiotics in the respondent's herd, rather

442 than issues related to the use of antibiotics in livestock production more generally. It should

443 be noted that the lower the mean ranking score attached to each question in Table 9, the

444 stronger respondents' agreement with the proposition contained in that question.

445 The regression model results used to predict intention to reduce antibiotics use are shown in

446 Table 10. It can be seen that while some individual OA measures were significantly

447 correlated with intent, the predictive power of the composite measure was only borderline

448 statistically significant and other variables were better predictors. The single directly measured SN measure was the most significant predictor of intent to reduce antibiotic use. The negatively signed estimate suggests that for every 1 unit decline in rank score on the SN measure, there was a 1.44 decline in intention rank (where $1=$ strong agreement with intention and 5=strong disagreement with intention). Because lower scores mean higher intention and greater agreement, the signs must be reversed when interpreting the results i.e. the opinions of respected peers were seen to be a strong positive driver of intent to reduce antibiotic use.

A list of 31 socio-demographic variables were tested in the regression model, with three of these proving to be significant predictors of intent: the proportion of farm income derived from the dairy enterprise; the likelihood of still being in dairy production in five years; and the importance of increased consumer confidence in the safety of milk and milk products. This latter question captured a background business-related attitude i.e. the importance, to the respondent, of increasing public confidence in milk safety in the coming year. In the context of reduced use of antibiotics, respondents may have understood this statement in two ways. First, that reducing antibiotics use might increase consumer confidence by reducing potential antibiotic residues in milk. Second, that reduced use of antibiotics might decrease consumer confidence as it could be associated with higher disease risks in dairy herds. Reversing the 
sign on the MLE estimate for this variable (Table 10) showed that increased intent was associated with a decrease in concern over consumer perceptions of milk safety.

\section{Discussion and conclusion}

This paper reports on how we used the well-established social psychology TPB to explore the drivers and barriers that existed to intention to reduce antibiotic use among dairy farmers in England and Wales. The analysis was based on 71 dairy farmers, around $0.75 \%$ of the target population, a sample size considered large enough, relative to the size of the population, to provide an acceptable confidence interval. On all but one of the measured dimensions, the sample was very representative of the industry, providing confidence in the generalizability of the survey results. The exception to this was herd size. While a random sample draw was the objective, some well-understood self-selection bias towards larger producers was inevitable and has occurred. However, this over-representation of larger herds on the representativeness of the sample is lessened significantly by current restructuring trends in the UK dairy sector, with producer numbers falling heavily each year and average herd sizes rising. The self-selection bias seen in the sample, therefore, provided some measure of future-proofing for the survey results for two reasons. First, because those with larger farms, who enjoy economies of scale, are more likely to remain in farming than their smaller counterparts and, second, as time passes, the more representative of farming the sample will become.

Animal health and welfare issues were of great importance to the survey dairy farmers, ranking equal to the profitability of their dairy enterprise amongst their business goals. In terms of treatments for animal health problems, farmers were prepared to purchase antibiotics as necessary. Almost all the sample had a recent Herd Health Plan, although these would only be useful in disease prevention if farmers actually used them.

There was some indication from the survey responses that use of antibiotics for clinical mastitis and calf pneumonia had reached a limit as over $70 \%$ of the respondents thought 
that reducing antibiotic use in their dairy herds would be a good thing to do. However, whilst

493 farmers were well aware of concerns about antibiotic resistance in cows and humans, their

494 primary motivation for wanting to reduce use of antibiotics was not to reduce the risk of bacterial resistance but, rather, to save on medicine costs to their business.

Around $30 \%$ of respondents were not aware of concerns about the use of third and fourth generation cephalosporins leading to increased antibiotic resistance in bacteria in both people and animals. Whilst $90 \%$ of respondents believed they followed best practice, almost $50 \%$ were not aware of the RUMA guidelines on use of antimicrobials in cattle production; most farmers reported applying good practices and $14 \%$ admitted modifying the advised dosage. Just over $80 \%$ of respondents said they always finished the prescribed course of antibiotics and almost all thought it was important to keep treatment records.

Most farmers (60\%) believed that they already had the necessary skills to successfully reduce their use of antibiotics. The most influential source farmers used to help them make decisions on controlling and treating livestock disease was their own veterinarian. As almost $70 \%$ of respondents believed that their veterinarians would approve of them reducing future antibiotic usage, this strongly suggests that there is a positive advisory environment to achieving this goal. However, this should not be taken to mean that veterinarians, as the key advisory source, were necessarily advising this course of action.

There was a clear suggestion that around half of all respondents had either recently reduced their level of antibiotic usage, or were planning to do so. Whilst the reasons behind this were not elicited directly, some assumptions can be made based on respondents' beliefs and attitudes towards antibiotic usage. Whether such reduction was circumstantial or planned, is not clear. Nevertheless, before accepting this statistic as final, some thought should be

515 given to the issue of the 'value action gap'. The Theory of Reasoned Action states that 516 behaviours are shaped by attitudes towards those behaviours, subject to social norms 517 (Fishbein and Ajzen, 1975). On this basis, attitudes towards reducing antibiotics and stated 
intention use should be a good indicator of actual buying practice. However, numerous researchers have identified a difference between the values derived from consumer attitudes and behavioural intentions and actual behaviour (see, for example, Barr, 2004; Blake, 1999; and Lane and Porter, 2007). To the extent that societal pressure exists to reduce antibiotic use in livestock production, it is safe to assume that the effects of social desirability bias will be experienced here and so the percentage of farmers who stated an intention to reduce antibiotic use in the next 12 months should be treated as an upper estimate.

The relationship between personal attitudes and the perceived attitudes of peers need not necessarily mean a causal relationship as positive attitudes towards the outcomes of reducing antimicrobial use, if they are well attested, will be shared with peers. The lack of significant correlation between own attitude, or attitudes of peers, and perceived behavioural control implies that farmers' perception of whether they can achieve reduced antibiotic usage are not completely influenced by their perceptions of the value of the outcome.

Statistical analysis showed that intention to reduce future antibiotic use was only very weakly correlated with current and past antibiotic use practice, whilst the strongest driver appeared to be respondents' belief that their social and advisory network would approve of them doing this. Desire to reduce costs, where this would not impair the health and welfare of their stock, was also found to be a strong driver. Wider societal concerns about inappropriate antibiotics use appeared to resonate with the survey farmers in terms of public confidence in the safety of the milk they produced i.e. in terms of risk to the viability of their business. This outcome makes perfect sense if respondents assumed that consumers associate reduced antibiotic use with increased disease risk and, therefore, decreased milk safety. It is also reasonable, here, that respondents who were least motivated by consumer concerns over milk safety would have fewer qualms about the effect that reduced antibiotic use would have

542 on consumer opinion. However, the way in which respondents interpreted this question about consumer confidence in milk is unclear, because use of antibiotics might have been 
seen as both creating a health risk (due to antibiotic residues in milk) and reducing health risk (by reducing disease incidence in lactating cows). The value of this socio-economic variable in explaining farmers' attitudes to reducing antibiotic use may be, therefore, somewhat impaired. In this case, it might be appropriate to introduce a 'benchmark' figure so that farmers can compare themselves with others. This business sustainability imperative is also reflected in the socio-economic variables identified as best predictors of intention to reduce the use of antibiotics over the next year i.e. the proportion of farm income from milk production, and the stated likelihood of farmers remaining in such production. The higher the scores on these variables, the greater was the likelihood of positive intention to reduce antibiotic usage, suggesting that those with firm intent to remain in milk production wanted to avoid 'problems' in the years ahead.

\section{Recommendations for policy}

556 It has been seen above that farmers most likely to reduce antibiotic use were those who

557 derived a higher than average share of farm income from the dairy enterprise and were planning to continue operating a profitable dairy enterprise for the foreseeable future (i.e. have no immediate retirement plans). They were aware of, and concerned about, both the risk of misuse of antibiotics in causing antibiotic resistance in the dairy herd and also in the human population as well as consumer concerns about antibiotic residues in milk. They held the belief that, undertaken correctly, reductions in use of antibiotics could yield financial benefits to them, primarily in the form of reduced costs, without affecting the animal welfare of their dairy cows or their herds' milk output.

The strong correlation between farmer perception of the beliefs of social referents and intent to reduce antibiotic use, strongly suggests that policy makers should target these advisory groups and institutions with information on the means to achieving reductions in antibiotic use. Amongst these dairy industry social referents, priority should be given to veterinarians who were found to be, by far, the most influential bearing in mind that the majority of the 
570 respondents $(71 \%)$ met with their veterinarian monthly or more frequently. The information

571 that needs to be supplied to farmers would include: the role that sub-optimal use of

572 antibiotics has in causing antibiotic resistance; advice on best practice in antibiotic use i.e.

573 specific management actions or alternative treatments that would permit reductions in

574 antibiotic use without financial losses; data on cost savings that might be obtained from

575 reduced antibiotic use; and assurance that there are low risks to animal welfare from

576 reduced antibiotic use. Care will need to be taken as to how this information is provided to

577 dairy farmers as not all of them will be amenable to electronic communication. With the

578 absence of a publicly-funded advisory service, postal delivery of hard-copy brochures may

579 well be appropriate.

580 Acknowledgements

581 This paper results from Defra project OD0351. We are grateful to: Defra for funding this

582 project; the farmers who took part; Chris Garforth for work on study design; and Teresa

583 Hicks for skilled questionnaire design and accurate data entry.

584

585 References

586 Ajzen, I., 1991. The theory of planned behaviour. Organ. Behav. Hum. Dec. 50,179-211.

587 Anon., 2007. Risk management of antimicrobial use and resistance from food-producing

588 animals in Denmark. Ministry of Family and Consumer Affairs; Technical University of

589 Denmark; Danish Veterinary and Food Administration.

590 http://www.foedevarestyrelsen.dk/english/SiteCollectionDocuments/25 PDF word filer\%20ti

591 \%20download/05kontor/Risk management antimicrobia \%20use and\%20resistance Den

592 mark E.pdf

593 Anon., 2009. Veterinary Medicines: BVA poster promotes responsible use of antimicrobials.

594 Vet. Rec. 16, 609. Poster link:

595 http://www.bva.co.uk/public/documents/BVA Antimicrobials Poster.pdf 
596 Anon., 2011. News and reports: antimicrobial resistance: EC launches action plan to tackle 597 antimicrobial resistance. Vet. Rec. 169, 565-566.

598 Anon., 2012a. National action plan for the reduction of the risks of antibiotic resistance in 599 veterinary medicine. Ministère de l'agriculture, de l'agroalimentaire et de la forêt. 600 http://agriculture.gouv.fr/IMG/pdf/130208PlanABR-GB-2012-BD cle8786a1.pdf

601 Anon., 2012b. News and reports: veterinary medicines: VMD decides to ban advertising of 602 antimicrobials to animal keepers. Vet. Rec. 171, 385.

603 Anon., 2013. The UK five year antimicrobial resistance strategy 2013 to 2018. Department of 604 Health, London, 43 pp.

605 https://www.gov.uk/government/publications/uk-5-year-antimicrobial-resistance-strategy606 2013-to-2018. Accessed June 2014.

607 Anon., 2014a. Reduced and responsible: policy on the use of antibiotics in food-producing 608 animals in the Netherlands. Ministry of Economic Affairs, The Hague, The Netherlands. 609 (February 2014). http://goo.gl/QXecRK Accessed 20 May 2014.

610 Anon., 2014b. Milk quality improves in UK herds. Farmers' Weekly 7 March 2014, 35.

611 Anon., 2014c. Code of Practice on the responsible use of animal medicines on the farm.

612 Veterinary Medicines Directorate (VMD). December 2014.

613 https://www.gov.uk/government/publications/responsible-use-of-animal-medicines-on-the614 farm (accessed 20 March 2015)

615 Armstrong, J.S., Overton, T.S., 1977. Estimating non response bias in mail surveys. J. 616 Marketing Res. 14, 396-407.

617 Barbosa, T.M., Levy, S.B., 2000. The impact of antibiotic use on resistance development 618 and persistence. Drug Resist. Update. 3, 303-311. 
619 Barclay, S., Todd, C., Finlay, I., Grande, G., Wyatt, P., 2002. Not another questionnaire!

620 Maximising the response rate, predicting non-response bias and assessing non-response

621 bias in postal questionnaire studies of GPs. Fam. Pract. 19, 105-111.

622 Barr, S., 2000. Are we all environmentalists now? Rhetoric and reality in environmental

623 action. Geoforum. 35, 231-249.

624 Blake, J., 2009. Overcoming the 'value-action gap' in environmental policy: tensions

625 between national policy and local experience. Loc. Env.: The Int. J. Just. and Sust. 4, 257-

626278.

627 British Cattle Veterinary Association, 2014. Medicine residues in milk-guidance.

628 http://www.bcva.eu/bcva/sites/default/files/PF502 004\%20BCVA\%202014\%20Milk\%20Resi

629 due\%20Poster.pdf. Published 9 August 2014.

630 Busani, L., Graziani, C., Franco, A., Di Egidio, A., Binkin, N., Battisti, A.,2004. Survey of the

631 knowledge, attitudes and practice of Italian beef and dairy cattle veterinarians concerning the

632 use of antibiotics. Vet. Rec. 155, 733-738.

633 Crowne, D.P., Marlowe, D., 1960. A new scale of social desirability independent of

634 psychopathology. J. Consult. Psychol. 24, 349-354.

635 DairyCo, 2013 Dairy statistics. An insider's guide 2013. DairyCo, Stoneleigh, UK.

636 De Briyne, N., Atkinson, J., Pokludova, L., Borriello, S.P., Price, S., 2013. Factors influencing

637 antibiotic prescribing habits and use of sensitivity testing amongst veterinarians in Europe.

638 Vet. Rec. 173, 475.

639 http://veterinaryrecord.bmj.com/content/early/2013/09/25/vr.101454.full.html

640 Defra (Department for Environment, Food and Rural Affairs), 2013a. Agriculture in the

641 United Kingdom, 2012. TSO, London, UK. 
642 Defra, 2013b. Farm business management practices in England 2011/12.

643 http://www.gov.uk/government/statistics/farm-business-management-practices. Published 21

644 May 2013.

645 Escher, M., Vanni, M., Intorre L., Caprioli A., Tognetti, R., Scavia, G., 2011. Use of

646 antimicrobials in companion animal practice: a retrospective study in a veterinary teaching

647 hospital in Italy. J. Antimicrob. Chemoth. 66, 920-927.

648 European platform for the responsible use of medicines in animals (EPRUMA), 2008. Best-

649 practice framework for the use of antimicrobials in food-producing animals in the EU. $14 \mathrm{pp}$.

$650 \quad$ www.epruma.eu

651 Fishbein, M., 2000. The role of theory in HIV prevention. AIDS Care. 12, 273-278.

652 Fishbein, M., Ajzen, C., 1975. Belief, attitude, intention and behaviour: an introduction to 653 theory and research. Addison-Wesley, Reading, MA.

654 Fishbein, M., Cappella, J.N., 2006. The role of theory in developing effective health 655 communications. J. Communic. 56, S1-S17.

656 Fishbein, M., Yzer, M.C., 2003. Using theory to design effective health behaviour 657 interventions. Communic. Theor. 13, 164-183.

658 Friedman, D.B., Kanwat, C.P., Headrick, M.L., Patterson, N.J., Neely, J.C., Smith, L.U., 659 2007. Importance of prudent antibiotic use on dairy farms in South Carolina: a pilot project 660 on farmers' knowledge, attitudes and practices. Zoonoses Public Health. 54, 366-375.

661 Garforth, C.J., McKemey, K., Rehman, T., Tranter, R.B., Cooke, R.J., Park, J.R., Dorward, 662 P.T., Yates, C.M., 2006. Farmers' attitudes towards techniques for improving oestrus 663 detection in dairy herds in South West England. Livest. Sci. 103, 158-168. 
664 Garforth, C.J., Bailey, A.P.,Tranter, R.B., 2013. Farmers' attitudes to disease risk

665 management in England: a comparative analysis of sheep and pig farmers. Prev. Vet. Med.

$666110,56-466$.

667 Gibbons, J.F., Boland, F., Buckley, J.F., Butler, F., Egan, J., Fanning, S., Markey, B.K., 668 Leonard, F.C., 2013. Influences on antimicrobial prescribing behaviour of veterinary 669 practitioners in cattle practice in Ireland. Vet. Rec. 172, 14.

670 Grave, K., Torren-Edo, J., Mackay, D., 2010. Comparison of the sales of veterinary

671 antibacterial agents between 10 European countries. J. Antimicrob. Chemoth. 65, 2037-

6722040.

673 Groves, R.M., 2006. Non-response rates and non-response bias in household surveys.

674 Public Opin. Quart. 70, 646-675.

Kirk-Wilson, R., 2008. Review of uptake of FSA Food Assurance Scheme guidance by UK Scheme operators for the Food Standards Agency. FSA, London, UK.

Landers, T.F., Cohen, B., Wittum, T.E., Larson, E.L., 2012. A review of antibiotic use in farm animals: perspective, policy and potential. Public Health Rep. January-February, 127, 4-21.

Lane, B., Potter, S., 2007. The adaption of cleaner vehicles in the UK: exploring the consumer 'attitude-action gap'. J. Clean. Prod. 15, 1085-1092.

Levy, S., 2014. Reduced antibiotics use in livestock: how Denmark tackled resistance. Environ. Heal. Persp. 122, A160-A165. http://ehp.niehs.nih.gov/122-A160/ response bias in postal surveys. Public Health Nurs. 26, 95-105. health. Clin. Microbiol. Rev. 24, 718-733. 
687 OIE (World Organisation for Animal Health), 2013. Terrestrial Animal Health Code.

688 Veterinary Public Health. Vol. 1, Section 6, $2^{\text {nd }}$ edition. OIE, Paris, France.

689

Pederson, K.B., Aarestrup, F.M., Jensen, N.E., Bager, F., Jensen, L.B., Jorsal, S.E.,

690 Nielsen, T.K., Hansen, H.C., Meyling, A., Wegener, H.C., 1999. The need for a veterinary

691 antibiotic policy. Vet. Rec.145, 50-53.

692 Prescott, J.F., 2014. The resistance tsunami, antimicrobial stewardship, and the golden age 693 of microbiology. Vet. Microbiol. 171, 273-278.

694 RUMA (Responsible Use of Medicines in Agriculture), 2004. Responsible use of

695 antimicrobials in pig production. Responsible use of medicines in agriculture alliance

696 guidelines for farmers. Accessed online 02/02/2012.

697 http://www.ruma.org.uk/guidelines/antimicrobials/short/pig.pdf

Statistical Analysis System, SAS Inc., Rayleigh, North Carolina, USA.

699 Teale, C.J., Moulin, G. 2012. Prudent use guidelines: a review of existing veterinary 700 guidelines. Rev. Sci. Tech. Off. Int. Epiz. 31, 343-354.

701 Tranter, R.B., Swinbank, A., Jones, P.J., Banks, C.J., Salter, A.M., 2011. Assessing the 702 potential for the uptake of on-farm anaerobic digestion for energy production in England.

703 Energ. Policy. 39, 2424-2430.

704

WHO (World Health Organisation), 2000. WHO global principles for the containment of

705 antimicrobial resistance in animals for food. Report of a WHO consultation with the participation of the Food and Agriculture Organization of the United Nations and the Office International des Epizooites. Geneva, Switzerland. 
709 WHO, 2014a. Strategic and technical advisory group on antimicrobial resistance: report of 710 the second meeting. 14-16 April 2014. WHO, Geneva, Switzerland.

711 WHO, 2014b. Additional global, regional and national strategies and plans to address 712 antimicrobial resistance. Dec 2014. WHO, Geneva, Switzerland.

713 http://www.who.int/drugresistance/global action plan/General and national plans amr De $714 \quad$ c 2014.pdf (accessed 20 March 2015) 